\title{
A pareto design of evolutionary hybrid optimization of ANFIS model in prediction abutment scour depth
}

\author{
HAMED AZIMI $^{1,2} \mathbb{D}$, HOSSEIN BONAKDARI ${ }^{1,2}$, ISA EBTEHAJ $^{1,2}$, SAEID SHABANLOU $^{3, *} \mathbb{D}$, \\ SEYED HAMED ASHRAF TALESH ${ }^{4}$ and ALI JAMALI ${ }^{4}$ \\ ${ }^{1}$ Department of Civil Engineering, Razi University, Kermanshah, Iran \\ ${ }^{2}$ Environmental Research Center, Razi University, Kermanshah, Iran \\ ${ }^{3}$ Department of Water Engineering, Kermanshah Branch, Islamic Azad University, Kermanshah, Iran \\ ${ }^{4}$ Department of Mechanical Engineering, University of Guilan, Rasht, Iran \\ e-mail: azimi86hamed@gmail.com; bonakdari@yahoo.com; isa.ebtehaj@gmail.com; \\ Saeid.shabanlou@gmail.com; hamedashraf83@gmail.com; ali.jamali@guilan.ac.ir
}

MS received 24 January 2019; revised 10 May 2019; accepted 14 May 2019; published online 27 June 2019

\begin{abstract}
In this paper, a novel pareto evolutionary structure of adaptive neuro-fuzzy inference system (ANFIS) network is presented for abutment scour depth predicting. The genetic algorithm (GA) and singular value decomposition (SVD) is utilized in optimizing design of nonlinear antecedent parts and linear consequent parts of TSK-type of fuzzy rules simultaneously in ANFIS design for the first time. To this end, first the parameters affecting the scour in the vicinity of abutments are detected. After that, 11 ANFIS-GA/SVD models are introduced through the combination of the parameters affecting the scour. Based on the modeling results, the ANFIS-GA/SVD models predict the scour around abutments with a reasonable accuracy. The superior model forecasts more than $63 \%$ of scours with an error of less than $8 \%$. The correlation coefficient $(R)$ for the model is computed roughly 0.978 . The value of the average discrepancy ratio for the model is obtained 0.981 . In addition, the results of the sensitivity analysis demonstrate that the Froude number $(F r)$ and the ratio of the flow depth to the radius of the scour hole $(h / L)$ are the most noticeable parameters affecting the scour depth in the vicinity of the abutments. Ultimately, a comparison between the superior model and the previous studies are presented which reveal that the current study has better performance to predict scour depth around abutments.
\end{abstract}

Keywords. Abutment scour depth; ANFIS; genetic algorithm (GA); pareto; singular value decomposition (SVD).

\section{Introduction}

\subsection{An overview}

Generally, abutments are used for stabilization of marine structures located in coastal regions and rivers. Abutments are widely utilized at the ends of a bridge span in order to transfer loads from bridge deck to foundation. One of the most important parameters in designing abutments is the scour depth estimation near such structures and failure to pay attention to it leads to instability of structures. Owing to the importance of abutments, many laboratories and numerical investigations have been done on the pattern of the scour occurring around abutments.

*For correspondence

\subsection{Experimental studies}

Melville [1] carried out a research to measure the local scour depth near abutments. He analyzed the effects of geometric characteristics of abutments, sediment properties and flow hydraulic parameters on the scour pattern around such structures. Lim [2] investigated the scour pattern around rectangular abutments in clear-water conditions. Through the analysis of the experimental results, he eventually put forward an equation for estimating local scour around abutments. The formula provided estimated scour depths in terms of the shape of the abutment and sediment properties. In addition, Melville [3] conducted an analytical study to provide an approach for computing the scour depth near abutments and piers. The approach predicts scour depths in terms of flow hydraulic parameters, foundation dimensions, sediment properties and abutments geometric. In clear-water conditions, Oliveto and Hager [4] established a laboratory test to examine the scour depth near abutments and piers. By measuring the experimental data, they also 
suggested an equation for approximating the scour depth around such structures. They compared the results obtained by the proposed relationship with the experimental values mentioned in other literatures and proved that this relationship is sufficiently accurate. Coleman et al [5] divided abutments into two categories including short abutments and long abutments for clear-water and uniform sediment conditions and evaluated the scour depth in their vicinity. Dey and Barbhuiya [6] carried out an experimental survey to study the scour pattern around abutments with different shapes shapes in clear-water conditions for non-uniform and uniform sediments. They also demonstrated that the length reduction of abutments as well as increasing in sediment dimensions and the flow depth lead to increase the scour depth. Furthermore, Dey and Barbhuiya [7] studied the influence of armored beds on scour depths in the vicinity of the short abutments in clear-water conditions. Radice [8] examined sediment kinematics for the scour occurring in the vicinity of rectangular abutments. They evaluated variations of bed sediment concentrations versus the magnitude of flow velocity. Ballio [9] studied the effects of constriction on the scour occurring around rectangular abutment by establishing a laboratory test programme. They proposed an enhancement function at the time of constriction occurrence for the scour prediction around abutments in clear-water conditions. Recently, Abdelaziz and Lim [10] measured experimentally scour near $45^{\circ}$ wing wall setback abutments within a compound flume. Also, Abid and Hong [11] studied on the deepest point of scouring around abutments in compound flumes. Hong and Abid [12] examined the influence of flow contraction on the abutment scouring for various lengths of abutment in a laboratory.

\subsection{Artificial intelligence studies}

Nowadays, soft computations and various neural network algorithms are employed as efficient tools in predicting non-linear and complex phenomena. Soft computations are widely used in pattern cognition of engineering phenomena, for example, in simulating the discharge capacity of weirs or estimating of sediment transport in sewage canals and other fields [13-19]. In addition, numerous studies have been performed for simulating the scour pattern around hydraulic structures by means of soft computations. Azmathullah et al [20] forecasted the scour depth after the ski jump at the downstream of ogee spillways using a feed forward neural network model. Bateni and Jeng [21] utilized the ANFIS to model the scour dimensions near piers. They introduced two input groups for their model. The first included data obtained from parameters with dimensions and the second consisted of dimensionless data. They showed that the ANFIS model predicted scour depths better than widths. Firat and Gungor [22] estimated the scour pattern in the vicinity of circular piers by means of Feed
Forward Neural Networks (FFNN) and Generalized Regression Neural Networks (GRNN) models. They also compared the modeling results to empirical formulas and the regression models and state that the GRNN predicted scour depths with reasonable accuracy. Kaya [23] simulated the scour behavior around piers by means of the artificial neural networks (ANNs). The results concluded from a sensitivity analysis indicated that the scour was determined by means of the base shape and other parameters. Muzzammil [24] simulated the scour near abutments by employing ANFIS, regression model and ANNs. The results of the numerical study proved the higher accuracy of the ANFIS model in predicting the scour around bridge abutments. Also, Muzzammil and Alam [25] estimated the scour depth in the vicinity of abutments using ANFIS network and regression method. They stated that the ANFIS had better performance. Azamathulla [26] simulated the scour process occurring around bridge abutments with various shapes by means of the gene-expression programming (GEP). The results from a sensitivity analysis conducted for the model showed that the shape coefficient parameter and the ratio of the length of abutment to the average size of sediments were the most effective parameters. Najafzadeh et al [27] estimated the scour depth of abutments for live-bed and clear-water conditions by means of the Group Method of Data Handling (GMDH). The results of the model were compared with support vector machine (SVM) and traditional equations and proved that the GMDH model had better performance. Sharafi et al [28] estimated the scour around abutments using the SVM. Furthermore, Ebtehaj et al [29] presented an artificial intelligence model for predicting the scour depth near abutments using the selfadaptive evolutionary extreme learning machine (SAELM). Azimi et al [30] optimized an ANFIS model for simulating the scour depth in the vicinity of the bridge piers.

\subsection{Study subject}

On the one hand, abutments are extensively applied under bridge decks to transfer live and dead loads to pier foundations. Additionally, owing to currents and waves, scour phenomenon might occur in the vicinity of abutments. This problem may threaten the stability of these types of structures and sufficient measures should be taken so as to prevent and mitigate the scouring.

On the other hand, a lot of surveys have been done on the application of artificial intelligence (AI) and soft computing (SC) techniques in estimating engineering issues on which the number of ongoing studies are increasing. However, based on the previous works, in spite of the significance of awareness about scour around abutments in designing bridges and piers, limited AI studies have focused on the issue. According to the authors' knowledge, other studies applied various SC models such as genetic algorithm-support vector regression [31], ANN and ANFIS [32], GMDH 
[27] and ANFIS [33], extreme learning machine [34] to model the scour in the vicinity of abutments and piers. Therefore, there is no study to simulate the scour around abutments using a meta-heuristic multi-objective AI model.

Additionally, different optimization problems were introduced in multifarious fields $[35,36]$. This means that there are numerous algorithms such as least-square and gradient descent to train the ANFIS network. Despite the fact that these approaches are beneficial, they might have some bottlenecks like high-volume of computations or trapping in local optimum. Thus, it is required that other agile methods should be applied so as to optimize the computational algorithms.

Therefore, for the first time, the Genetic Algorithm (GA) as an evolutionary algorithm and the Singular Value Decomposition (SVD) approach as a strength AI technique in least square problems, are applied in topology design of ANFIS (ANFIS-DE/SVD). Also, the trade-off between two target functions including Prediction Error (PE) and Training Error (TE) are selected by the Pareto curve in this study. Considering that in the modeling using artificial intelligence methods, the data are divided into two sub-samples of training and testing, the performance of the model in both stages should be evaluated. Generally, in different studies, the criterion for examining a model is its performance in testing stage. Although the acceptable performance of the model in the test stage indicates the flexibility of the model for prediction, but because the number of data intended to train the model is greater than the test data, the performance of a model in training stage should also be considered. Hence, in this study, the performance of the AI model is examined using both of training and testing datasets. In fact, two objective functions are defined as TE and PE, and the trade-off between these two functions is selected by means of the Pareto curve, and reported as the optimal result.

In the current study, firstly, the most important input parameters affecting the abutment scour are presented and eleven hybrid models are developed. Secondly, methodology of applied numerical models including ANFIS, GA and SVD are introduced. Next, results from all the simulated models are analyzed precisely. Then, the superior model and the most effective input parameter are identified. Finally, a comparison between the best model and the previous works is presented.

\section{Scour hole depth around bridge abutments}

In this paper, the experimental data obtained by Dey and Barbhuiya [37] are utilized for verifying the results from the ANFIS-GA/SVD model. Their laboratory model was composed of a rectangular flume with the length, width and depth of $20 \mathrm{~m}, 0.9 \mathrm{~m}$ and $0.7 \mathrm{~m}$, respectively. Abutments were made of Perspex in the shapes of semicircular, vertical-wall and $45^{\circ}$ wing-wall. In figure 1 , the schematic of the experimental model developed by [37] is presented. (a)

(b)
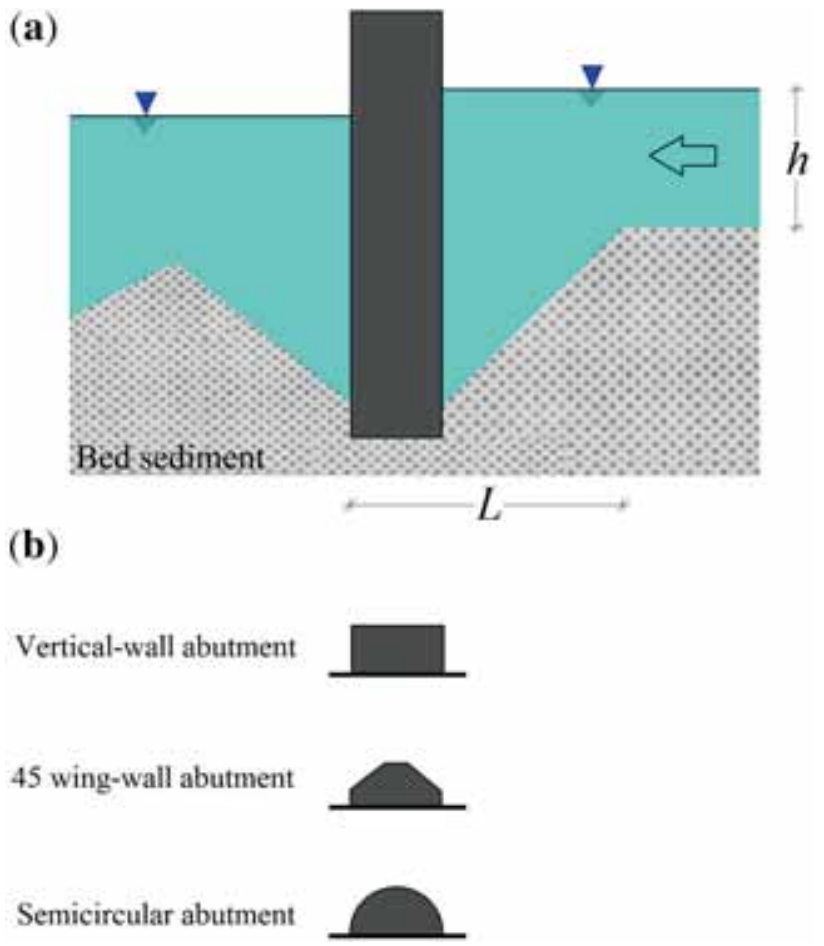

Figure 1. Schematic of Dey and Barbhuiya [37] model. (a) Cross-section, (b) view from above of abutments in different shapes.

Table 1. Range of geometric and hydraulic parameters of Dey and Barbhuiya [37] model.

\begin{tabular}{lccccc}
\hline $\begin{array}{l}\text { Dimensionless } \\
\text { parameters }\end{array}$ & Min. & Max. & Ave. & Variance & $\begin{array}{c}\text { Standard } \\
\text { division }\end{array}$ \\
\hline$F r$ & 0.056 & 0.396 & 0.140 & 0.003 & 0.058 \\
$h / L$ & 0.385 & 6.250 & 2.439 & 2.043 & 1.429 \\
$d_{50} / L$ & 0.002 & 14.522 & 0.014 & 0.0001 & 0.013 \\
$\sigma_{g}$ & 0.75 & 98.75 & 13.522 & 638.707 & 25.273 \\
$d_{s} / L$ & 0.646 & 4.350 & 1.835 & 0.436 & 0.660 \\
\hline
\end{tabular}

In table 1 , the range of the geometric and hydraulic parameters of Dey and Barbhuiya [37] model are listed. In this paper, the flow Froude number $(F r)$, flow depth $(h)$ the average diameter of sediments $\left(d_{50}\right)$ the ratio of the scour hole $\left(d_{s}\right)$ to the radius of the scour hole $(L)$ parameters are made dimensionless. In addition, $\sigma_{g}$ is the geometric standard deviation of sediments [37].

The scour around bridge abutments for non-uniform sediments depend on flow hydraulic characteristics, the shape of abutments and sediment geometric properties [27]:

$$
d_{s}=f\left(\rho, \rho_{s}, U, h, L, K_{s}, g, d_{50}, \sigma_{g}\right)
$$

where $\rho, \rho_{s}, v, \mathrm{U}, h, \mathrm{~L}, \mathrm{~K}_{\mathrm{s}}, \mathrm{g}, \mathrm{d}_{50}$ and $\sigma_{g}$ are fluid density, sediment density, kinematic viscosity, average velocity of flow, flow depth, radius of scour hole, shape coefficient of the bridge abutment, gravitational acceleration, average 


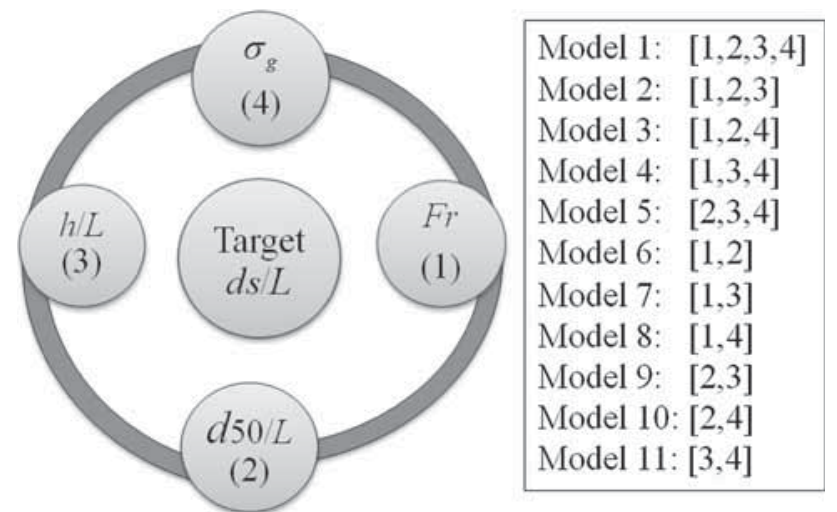

Figure 2. Layout of input parameters used for ANFIS-GA/SVD models.

diameter of sediments and geometric standard deviation of sediment particles distribution. The fluid density, sediment density and kinematic viscosity parameters are constant and the Froude number is equal to $F r=U / \sqrt{g \cdot y}$. In this study, the effects of the Froude number $(U / \sqrt{g \cdot y})$, the ratio of the average diameter of sediments to the radius of the scour depth $\left(\mathrm{d}_{50} / L\right)$, the ratio of the flow depth to the radius of the scour hole $(\mathrm{h} / \mathrm{L})$ and the geometric standard deviation of the distribution of sediment particles $\left(\sigma_{g}\right)$ on the scour hole depth are investigated. Thus, Eq. 1 is written as follows:

$$
\mathrm{d}_{\mathrm{s}} / L=\mathrm{f}\left(U / \sqrt{g \cdot y}, \mathrm{~d}_{50} / L, \mathrm{~h} / \mathrm{L}, \sigma_{g}\right)
$$

Then, eleven ANFIS-GA/SVD models are developed through the combination of the input parameters specified in table 1. The combination is illustrated in figure 2. To predict the depth of the scour hole formed around bridge abutments, 276 experimental data are employed in which $70 \%$ of them are applied for training the ANFIS-GA/SVD models and the remaining (30\%) for testing the modeling process.

\section{Adaptive neuro-fuzzy inference systems (ANFIS)}

In this section, first the modeling procedure by the ANFIS system is discussed. Then, the application of the singular value decomposition (SVD) and genetic algorithm (GA) methods in modeling the abutment scour depth are explained. GA and SVD optimally approximate the non-linear parameters of the antecedent part and the linear variables of the succedent section related to the fuzzy rules, respectively.

\subsection{Anfis}

The ANFIS is a mapping of internal space to the external environment consisting of a set of TSK type fuzzy rules.
Actually, this system tries to find the function $\hat{f}$ to approximate the behavior of the actual function $f$ as accurate as possible. For example, consider a system with $n$ inputs and one output with $\mathrm{M}$ pairs of data as multi-inputssingle-output. ANFIS estimates output values so that the different between estimated outputs and system actual outputs being minimum, thus:

$$
\begin{gathered}
\hat{y}_{1}=\hat{f}\left(x_{i 1}, x_{i 2}, \ldots, x_{i n}\right)(i=1,2, \ldots, M) \\
E=\sum_{i=1}^{M}\left(\hat{f}\left(x_{i 1}, x_{i 2}, \ldots, x_{i n}\right)-y_{i}\right)^{2} \rightarrow \text { Min }
\end{gathered}
$$

For a system with $n$ inputs and one output, each IFTHEN fuzzy rule is written as follows:

$$
\begin{aligned}
& \text { Rule }_{1}: \text { if } x_{1} \text { is } A_{l}^{\left(j_{1}\right)} \text { AND } x_{2} \text { is } A_{1}^{\left(j_{2}\right)}, \ldots, x_{n} \text { is } A_{1}^{\left(j_{n}\right)} \\
& \text { then } y=\sum_{i=1}^{n} W_{i}^{l} x_{i}+W_{0}^{l}
\end{aligned}
$$

where $\quad l=\{1,2, \ldots, N\}, \quad j_{i}=1,2, \ldots, r \quad$ and $\quad W^{l}=$ $\left\{w_{1}^{l}, w_{2}^{l}, \ldots, w_{n}^{l}, w_{0}^{l}\right\}$ are the set of parameters of the subsequent part related to fuzzy rules. The number of linear consequent parameters is equal to $N(n+1)$. Each fuzzy set $A^{(i)}=\left\{A^{(1)}, A^{(2)}, \ldots, A^{(r)}\right\}$ represents one of input variables and $j_{i}=\{1,2, \ldots, r\}$ is the membership function (MF) for each input variable. Fuzzy sets are defined as Gaussian MFs with good performance in recent studies $[30,38]$ in the range of $\left[-\alpha_{i},+\beta_{i}\right](i=1,2, \ldots, n)$. In this case, domains are chosen for each $x_{i} \in\left[-\alpha_{i},+\beta_{i}\right]$, there is a $A^{(j)}$ whose membership degree related to its MF is opposite zero $\left(\mu_{i}^{(j)}\left(x_{i}\right) \neq 0\right)$. Each fuzzy set $A^{(j)}(j \in\{1,2, \ldots, r\})$ in the form of Gaussian functions is calculated by the following relationship:

$$
\mu_{A^{(j)}}\left(x_{i}\right)=\exp \left(\left(-\frac{x_{i}-c_{j}}{2 \sigma_{j}}\right)^{2}\right) .
$$

Here, $\sigma_{j}$ is adjustable center and $c_{j}$ is variances center. It should be noted that the number of variables of the antecedent section of the ANFIS model equals to the multiplication of the size of the input vector $(n)$ by the fuzzy sets existing in this part $(n r)$. The fuzzy set mentioned in Eq. (5) is a fuzzy relationship in $U \times R$, in which $A^{(i)}$ represents fuzzy sets in $U_{i}$. So:

$$
\begin{gathered}
U=U_{1} \times U_{2} \times \cdots \times U_{n} \\
\text { Rule }=A^{\left(j_{1}\right)} \times A^{(j 2)} \times \cdots \times A^{(j n)} \rightarrow y
\end{gathered}
$$

By considering the implication relation as the algebraic sum of Mamdani, the order of an IF-THEN fuzzy rule is computed as follows: 


$$
\mu_{\text {Rule }}=\mu_{U}\left(x_{1}, x_{2}, \ldots, x_{n}\right)
$$

where, $U=A_{l}^{\left(j_{1}\right)} \times A_{l}^{\left(j_{2}\right)} \times \cdots \times A_{l}^{\left(j_{n}\right)}$ and:

$$
\mu_{U}\left(x_{1}, x_{2}, \ldots, x_{n}\right)=\prod_{i=1}^{n} \mu_{A_{l}^{\left(j_{i}\right)}}\left(x_{i}\right)
$$

Also, in this relationship $\mu_{A_{\left(j_{i}\right)}}\left(x_{i}\right)$ represents the membership degree of the $x_{i}$ th input related to linguistic value of the $l$ th fuzzy rule $A_{l}^{\left(j_{i}\right)}$. By means of the singleton fuzzy maker, which is the inference engine of the multiplication of the sum of contributions related to each rule, the fuzzy system with a set including $N$ fuzzy rules is expressed as follows:

$$
f(X)=\frac{\sum_{l=1}^{N} y_{l}\left(\prod_{i=1}^{n} \mu_{A_{l}^{\left(j_{i j}\right)}}\left(x_{i}\right)\right)}{\sum_{l=1}^{N}\left(\prod_{i=1}^{n} \mu_{A_{l}^{\left(j_{i}\right)}}\left(x_{i}\right)\right)}
$$

The above relationship can be rewritten in a linear formation as follows:

$$
f(X)=\sum_{l=1}^{N} p_{l}(X) y_{l}+D
$$

here, $D$ represents the difference between actual values $(y)$ and $f(X) . p_{l}(X)$ is computed as follows:

$$
p_{l}(X)=\frac{\left(\prod_{i=1}^{n} \mu_{A_{l}^{\left(j_{i}\right)}}\left(x_{i}\right)\right)}{\sum_{l=1}^{N}\left(\prod_{i=1}^{n} \mu_{A_{l}^{\left(j_{i}\right)}}\left(x_{i}\right)\right)}
$$

Equation (14) is rewritten in matrix form for $M$ pairs of observational values $\left(X_{i}, y_{i}\right)(i=1,2, \ldots, M)$ as follows:

$$
Y=P W+D
$$

here, $P=\left[p_{1}, p_{2}, \ldots, p_{s}\right]^{T} \in R^{m \times S}, W=\left[w_{1}, w_{2}, \ldots, w_{s}\right]^{T} \in$ $R^{s}$ and $S=N(n+1)$.

It is worth noting that each $w_{i}$ vector related to the consequent part of the fuzzy rule includes $(n+1)$ members. Thus, the firing strength matrix $(P)$ is created through configuration of the internal environment by fuzzy rule sets.

It is obvious that the number of the data employed in the learning process is usually more than the coefficients related to the consequent section $(m \geq S)$. In other words, rules are too small which might lead to the least square estimation process calculating $\mathrm{W}$ coefficients. Therefore, the governing equation is transformed as follows:

$$
W=\left(P^{T} P\right)^{(-1)} P^{T} Y
$$

\subsection{Optimized design of ANFIS by GA}

Membership functions of input variables are considered in the Gaussian form with two parameters $c_{j}$ and $\sigma_{j}$ Eq. (6) which are adjustable. So, the total number of parameters existing within the input space is as follows:

$$
\text { Input Parameters }=\sum_{i=1}^{n} 2 \times r_{i}
$$

where $r$ is the vector of the MF for each parameter entering to the model and $\mathrm{n}$ represents the number of input variables. Parameters of Gaussian functions are extracted optimally using the GA. The application of GA in modeling ANFIS network starts by displaying $N(n+1)$ variables $c_{j}$ and $\sigma_{i}$ as a string containing sub-strings with a binary view. So, each sub-string belonging to the antecedent part in the rule set displays the ANFIS system as a binary representation. The fitness (Ф) of each string from binary numbers displaying the ANFIS system is computed by the following formula:

$$
\Phi=\frac{1}{E}
$$

here, $E$ is the objective function. The objective function is minimized via the evolutionary process which increases the fitness. The evolutionary process commences by random production of the initial population from binary strings in which each of them represents a solution for fuzzy components of the antecedent part. To optimize variables of input MFs in a multi-objective form using the GA, genetic parameters are as the number of population, the generation number, crossover and mutation. After generating the initial population, by transforming number to integers, the value of the objective function for each chromosome is computed. In this way, the educational data of linear coefficients of the output matrix are obtained and, then the value of the predicted error is obtained. This operation is carried out for each chromosome. After this stage, chromosomes are examined and selected according to specified criteria. The next stage is related to generate the populations by the crossover and mutation operators. The crossover operation is conducted by selecting two superior chromosomes from the previous generation population and a series of their bits are displaced and, as a result, a new chromosome is formed. In fact, this operation passes good features of previous generations to next generations based on the nature of gradual evolution. Another operator of the genetic algorithm for producing the next generation is mutation whereby by selecting a chromosome from the population of the previous generation, one of its bits is randomly selected and the number inside that bit is altered. In addition to produce a new chromosome, this operation prevents the program from getting stuck at local optimal points. After the production of the population, worse chromosomes which have the maximum error are eliminated. After that, chromosomes of the former generation are brought to the next generation and the gradual evolution operation is continued for the number of specified generations until reaching the optimal population. 


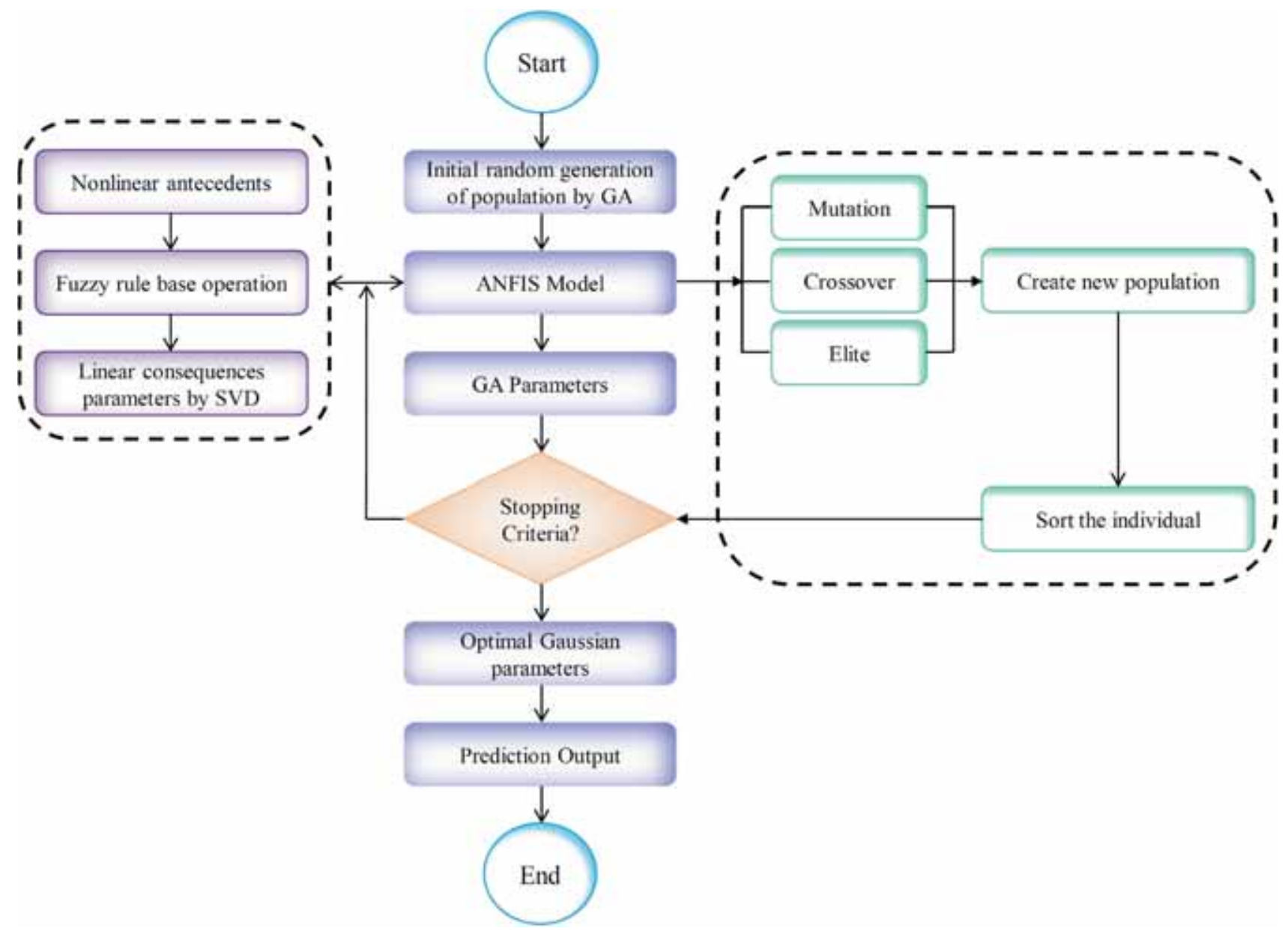

Figure 3. Flowchart of ANFIS-GA/SVD.

\subsection{Application of singular SVD in ANFIS design}

The most common problem in solving a system of equations is singularity, the closeness to the singularity of the coefficient matrix, or uneven number of unknowns or equations. In this case, the determinant of the coefficient matrix is zero. To solve the probable singularity problem in the governing equation (optimal determination of linear coefficients related to the subsequent section of TSK-type fuzzy rules), the SVD approach [39] as a strength numerical approach is utilized. In order to solve Eq. (14), first the modified reverse of the matrix $W$ is calculated, then optimal values of $W_{\text {rule }}$ are obtained as follows:

$$
W_{\text {Rule }}=V\left(\operatorname{diag}\left(\frac{1}{w_{j}}\right)\right) U^{T} Y
$$

where $U$ is a column-valued orthogonal matrix and $V^{T}$ is the transposed form of an orthogonal matrix. Therefore, the ANFIS models produced for predicting abutment scour depths, increase the fitness while the parameters related to the antecedent and consequent parts of TSK-type fuzzy rules are determined simultaneously by GA and SVD, respectively. In figure 3, the flowchart of the hybrid model provided in this simulation is drawn.

\subsection{Goodness of fit}

To examine the results from the numerical models in predicting the scour near abutments the Mean Absolute Percentage Error (MARE), Root Mean Squared Error (RMSE), correlation coefficient $(R), B I A S$, Scatter Index $(S I)$ and $\rho$ statistical indices are utilized:

$$
\begin{aligned}
& \text { MARE }=\frac{1}{n^{\prime}} \sum_{i=1}^{n^{\prime}}\left(\frac{\left|\mathrm{d}_{\mathrm{s}} / L_{(\text {(re edicted })_{i}}-\mathrm{d}_{\mathrm{s}} / L_{(\text {observed })}\right|}{} \mid\right) \\
& R M S E=\sqrt{\frac{1}{n^{\prime}} \sum_{i=1}^{n^{\prime}}\left(\mathrm{d}_{\mathrm{s}} / L_{(\operatorname{Pr} \text { edicted })_{i}}-\mathrm{d}_{\mathrm{s}} / L_{(\text {Observed })_{i}}\right)^{2}}
\end{aligned}
$$




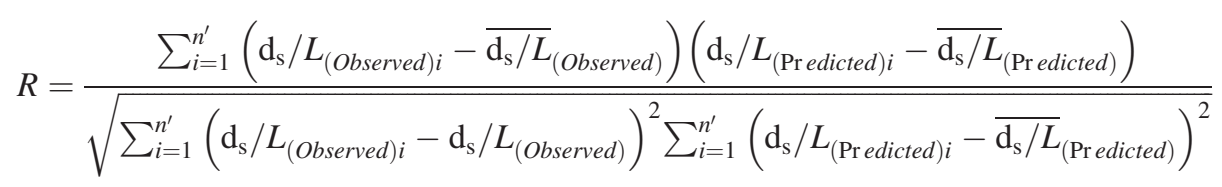

$$
\begin{gathered}
\text { BIAS }=\frac{1}{n^{\prime}} \sum_{i=1}^{n^{\prime}}\left(\mathrm{d}_{\mathrm{s}} / L_{(\operatorname{Pr} \text { edicted })_{i}}-\mathrm{d}_{\mathrm{s}} / L_{(\text {Observed })_{i}}\right) \\
S I=\frac{R M S E}{\overline{\mathrm{d}_{\mathrm{s}} / L_{(\text {Observed })}}} \\
\rho=\frac{S I}{1+R}
\end{gathered}
$$

where $\mathrm{d}_{\mathrm{s}} / L_{\text {(observed) } i}$ is the ratio of the scour depth to the radius of the experimental scour hole, $\mathrm{d}_{\mathrm{s}} / L_{(\text {Predicted }) i}$ is the ratio of the scour depth to the radius of the scour hole predicted by the numerical model, $\overline{\mathrm{d}}_{\mathrm{s} / L_{(\text {observed }) i}}$ is the average of the ratio of the scour depth to the radius of the experimental scour hole and $n^{\prime}$ represents experimental measurements. Generally, the closeness of the MARE, $R M S E, B I A S, S I$ and $\rho$ to zero signifies better performance of the numerical model. Furthermore, the closeness of the $R$ index to one reveals high correlation of the numerical model. The employed indices calculate the error between observed and numerical data and do not provide additional information about error distribution of the models. Thus, the TSx index is provided to describe the error distribution by the models. In other words, the TSx index is computed for the ANFIS-GA/SVD models:

$$
T S x=\frac{Y_{x}}{n} \times 100
$$

here, $Y_{x}$ represents the MARE values estimated by ANFIS$\mathrm{GA} / \mathrm{SVD}$ models whose error values are less than $x \%$.

\section{Evaluation of ANFIS-GA/SVD models}

The hybrid model provided in this study which simultaneously uses GA and SVD in optimizing ANFIS is employed in a dual objective way to increase flexibility and generalizability of the model. The objective functions defined in this approach include Predicting Error (PE) and Training Error (TE). In modeling using the ANFIS-GA/SVD method, the modeling performance is evaluated for both objective functions (TE and PE) and the model with the best performance in both objective functions is chosen as the optimized performance. In figure 4, the Pareto graph related to model 1 [Eq. (2)] is presented. In this figure, PE

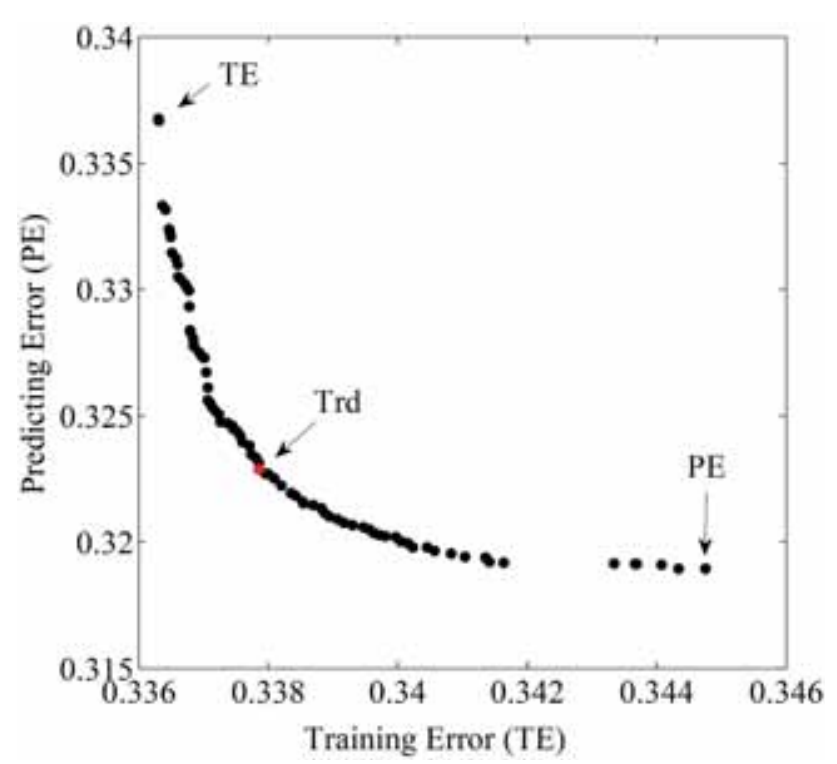

Figure 4. Pareto curve for TE and PE.

and TS are points with the maximum error value in learning and prediction modes, respectively. Trd as the trade-off related to the PE and TE points are chosen as the optimized model. These points are selected by means of the nearest ideal point (NIP) [40] method. Figure 5 illustrates the membership function values considered for modeling by ANFIS [related to model 1 defined in Eq. (2)]. The $X$ and $Y$ axes in this figure, represent the value of the input parameter of the model and the degree of membership associated with each of the membership functions for this parameter, respectively. According to the figure, three Gaussian functions are utilized for all inputs of the model in the conducted modeling. In table 2, the optimal values associated with Model 1 are listed.

In order to simulate the scour hole depth, first the experimental measurements are divided into two sub-samples including learning and test. The total number of the measurements used in this study is 276 , of which $70 \%$ are implemented to teach numerical models and the remaining $30 \%$ for testing the simulation. In this study, 11 different models are introduced through the combination of the parameters mentioned in Eq. (2). The combination was shown in figure 2. Furthermore, due to the need to define 

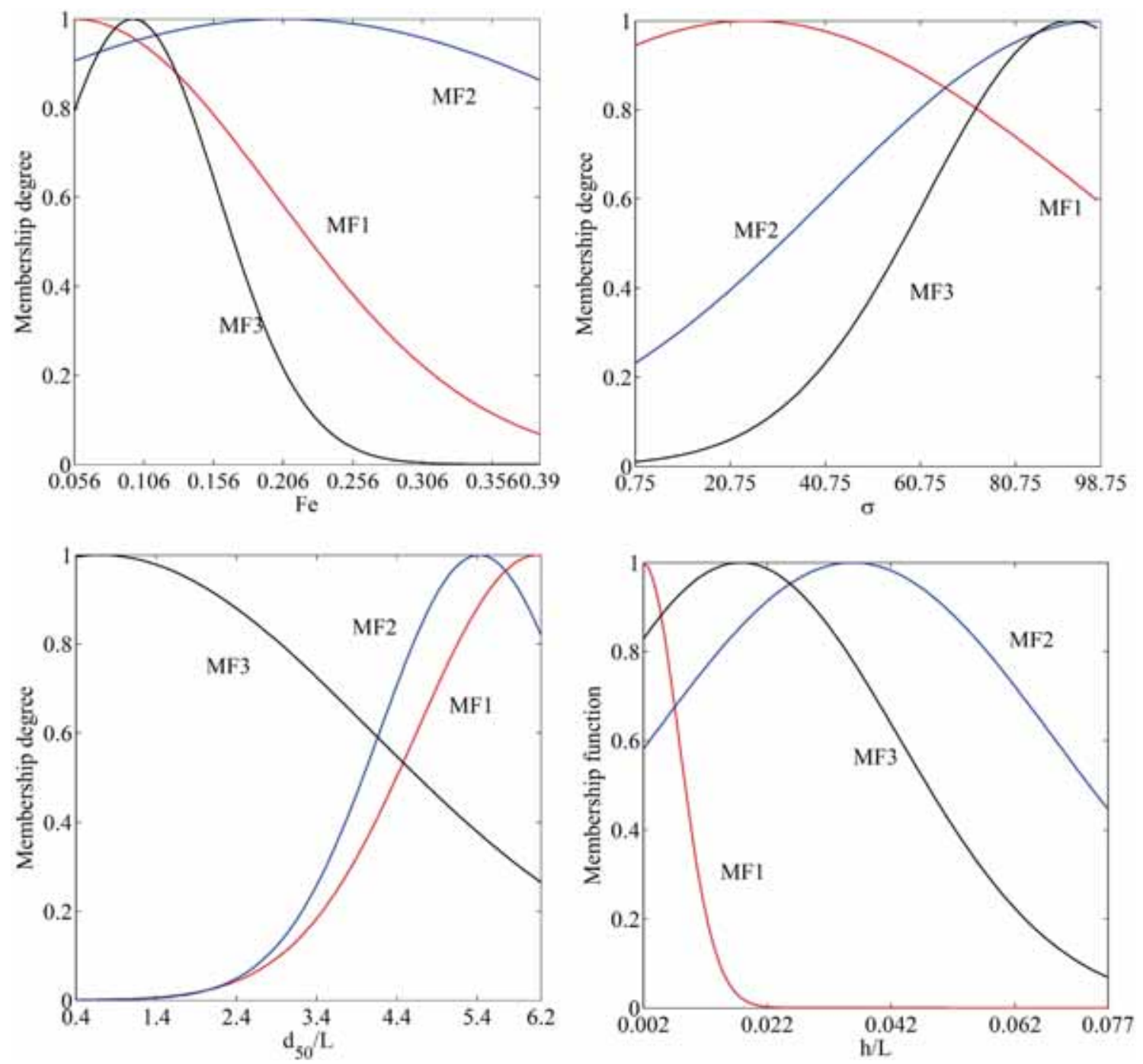

Figure 5. Optimum MF of trade-off design point.

Table 2.Optimum variables of Gaussian membership functions in trade-off point.

\begin{tabular}{ccccc}
\hline & $F r$ & $d_{50} / L$ & $h / L$ & $\sigma_{g}$ \\
\hline$\sigma$ & 0.144 & 1.498 & 0.006 & 71.783 \\
& 0.338 & 1.229 & 0.032 & 57.273 \\
& 0.062 & 3.376 & 0.026 & 30.194 \\
$C$ & 0.056 & 6.158 & 0.002 & 24.987 \\
& 0.207 & 5.424 & 0.036 & 98.750 \\
& 0.098 & 0.694 & 0.018 & 92.427 \\
\hline
\end{tabular}

the parameters of the genetic algorithm, the values of these parameters are as follows:

- Number of population $=200$

- Generation number $=300$

- Crossover $=0.7$

- Mutation = 0.1

\section{Results and discussion}

\subsection{Sensitivity analysis}

The values of MARE and RMSE for Model 1 to Model 11 in the test mode are arranged in table 3 . In addition, the variations of the statistical indices for all models in the test mode are depicted in figure 6. In addition, the error distribution and the scatter plot of the test results for Model 1 to Model 11 are presented in figures 7 and 8, respectively.

Model 1 is a function of the Froude number $(F r)$, the ratio of the average diameter of sediments to the radius of the scour hole $\left(\mathrm{d}_{50} / L\right)$, the ratio of the flow depth to the radius of the scour hole $(\mathrm{h} / \mathrm{L})$ and the geometric standard deviation of the sediment particle distribution $\left(\sigma_{g}\right)$. This model simulates the RMSE equal to 0.156 . For the model, about $43 \%$ of the results have an error less than $10 \%$ and about $44 \%$ of the data have an error more than $15 \%$. Also 
Table 3. MARE and RMSE for Model 1 to Model 11.

\begin{tabular}{lcc}
\hline Models & MARE & RMSE \\
\hline Model 1 & 0.156 & 0.319 \\
Model 2 & 0.068 & 0.141 \\
Model 3 & 0.093 & 0.201 \\
Model 4 & 0.066 & 0.145 \\
Model 5 & 0.207 & 0.494 \\
Model 6 & 0.066 & 0.138 \\
Model 7 & 0.065 & 0.135 \\
Model 8 & 0.065 & 0.138 \\
Model 9 & 0.104 & 0.237 \\
Model 10 & 0.217 & 0.497 \\
Model 11 & 0.118 & 0.255 \\
\hline
\end{tabular}

for Model 1, the BIAS, SI and $\rho$ are computed $0.263,0.168$ and 0.089 , respectively. As shown in figure 8, correlation coefficient $(R)$ is obtained 0.898. In addition, Models 2-5 simulate the depth of scour holes through the combination of three input parameters. For Model 2, the MARE and correlation coefficient are estimated 0.068 and 0.967,
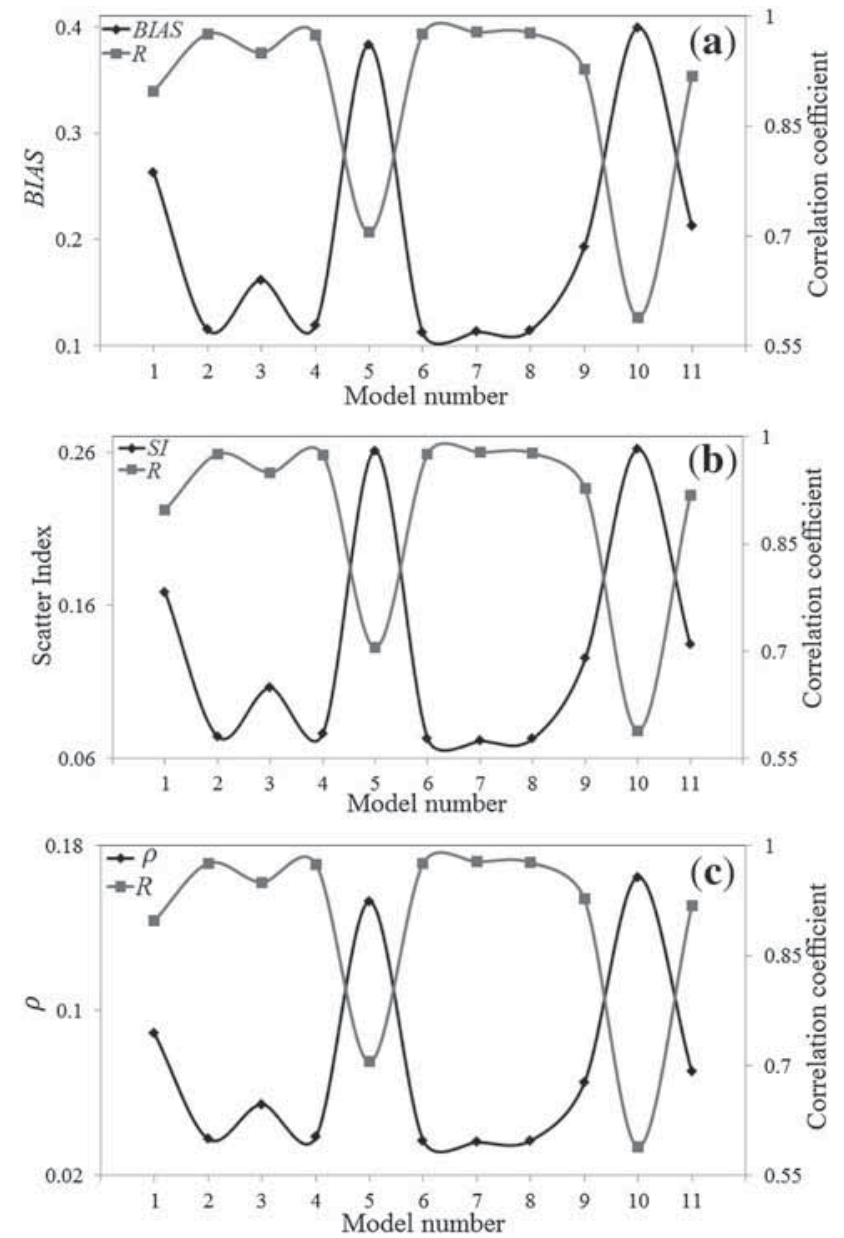

Figure 6. Variations of correlation coefficient $(R)$ versus (a) BIAS, (b) Scatter Index and (c) $\rho$.

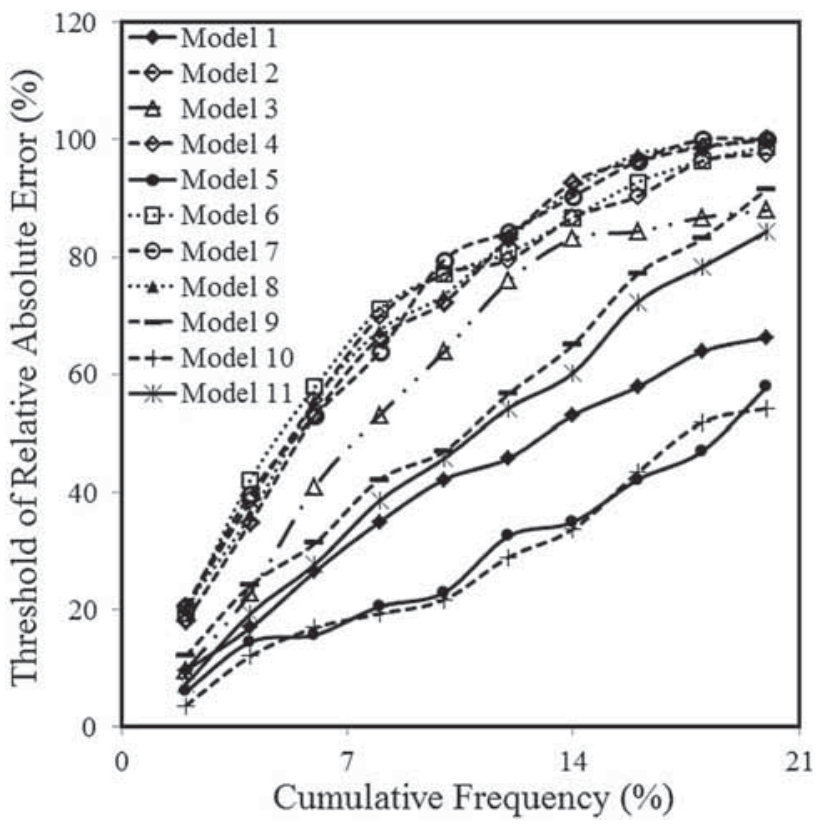

Figure 7. Error distribution for Model 1 to Model 11.

respectively. Additionally, RMSE is computed equal to 0.141 . The model simulates the target function by employing the Froude number, the ratio of the average diameter of sediments to the radius of the scour hole and the ratio of the flow depth to the radius of the scour hole. Model 2 simulates about $78 \%$ of the modeling results with an error less than $10 \%$ and about $10 \%$ of the data simulated by this model have an error more than $15 \%$. In contrast, $12 \%$ of the modeled scour values have an error between 10 and $15 \%$. For the model, the BIAS and $\rho$ are estimated 0.115 and 0.038 , respectively. Model 3 predicts the scour depth using three input parameters including $F r, \mathrm{~d}_{50} / L$ and $\sigma_{g}$. For the model, the RMSE and $R$ are forecasted 0.201 and 0.905 , respectively. In addition, for Model 3, the Scatter Index is approximated to 0.106 , while the $\rho$ is computed to 0.054 . This model predicts about $20 \%$ of the results with an error between 10 and 15 and $65 \%$ of the data have an error less than $10 \%$. Also, about $14 \%$ of the predicted scours have an error more than $15 \%$. According to the scatter plot, the correlation coefficient value for Model 4 is calculated as 0.975 , while the MARE, RMSE and BIAS for Model 4 are obtained as 0.066, 0.145 and 0.119, respectively. This model simulates the depth of scour in terms of the Froude number $(F r)$, the ratio of the flow depth to the radius of the scour hole $(\mathrm{h} / \mathrm{L})$ and the geometric standard deviation of sediment particle distribution $\left(\sigma_{g}\right)$. It should be noted that $72 \%$ of the results predicted by the model have an error less than $10 \%$. On the other hand, the SI and $\rho$ for Model 4 are obtained 0.076 and 0.039, respectively.

Model 5 is as a function of $\mathrm{d}_{50} / L, \mathrm{~h} / \mathrm{L}$ and $\sigma_{g}$ with the minimum accuracy amongst the models with three input 

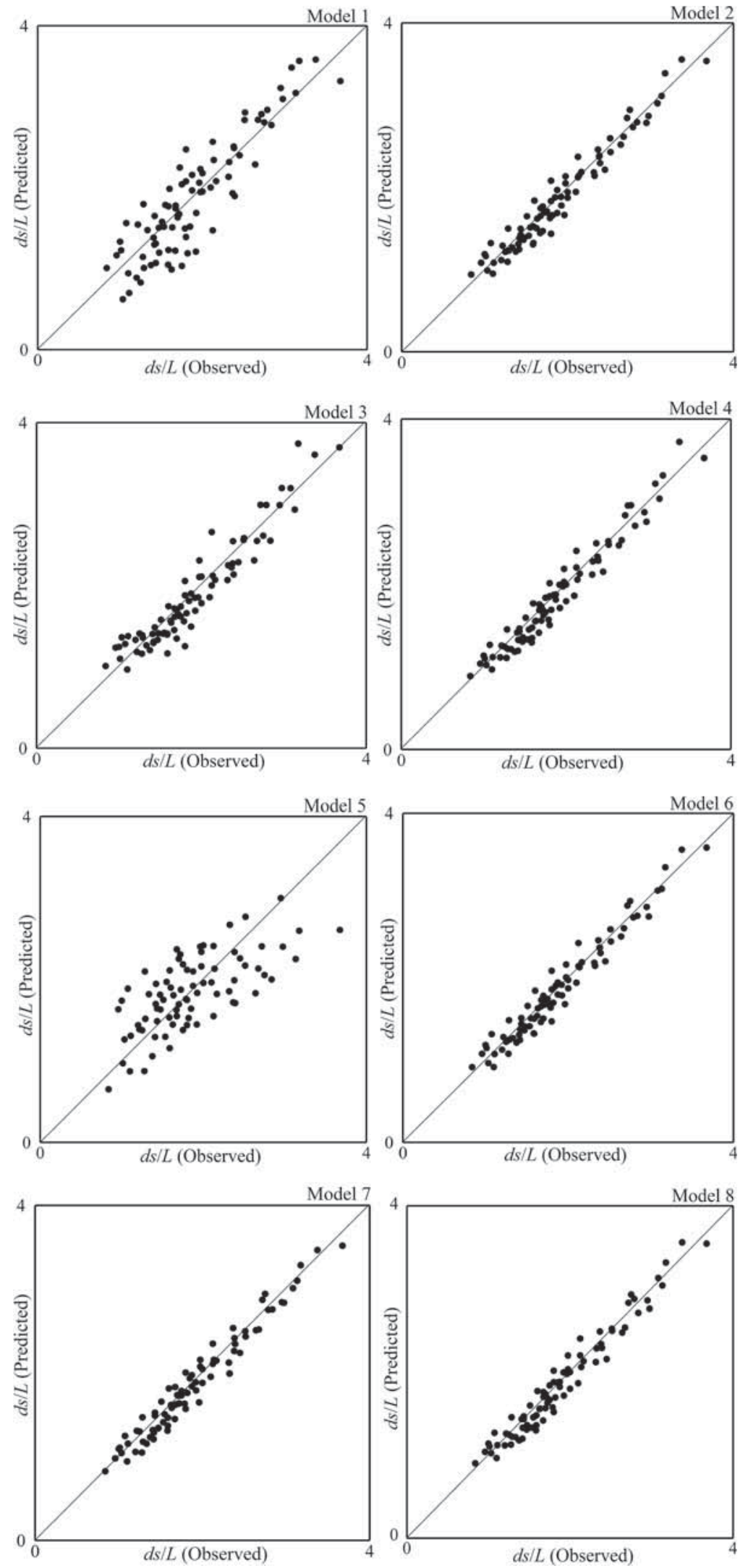

Figure 8. Scatter plot for Model 1 to Model 11. 


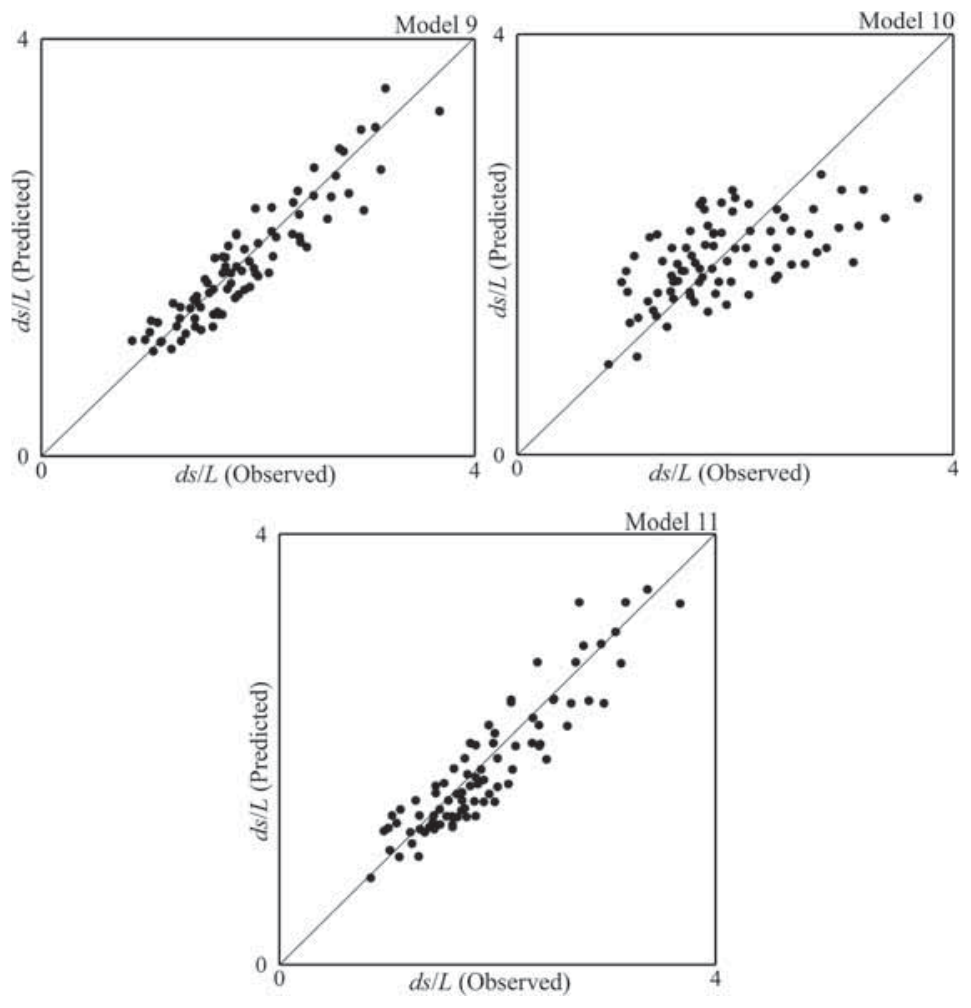

Figure 8. continued

variables. Model 5 calculates only $24 \%$ of the results with an error less than $10 \%$ and the remaining $64 \%$ have an error more than $15 \%$. The MARE, RMSE and $\rho$ for Model 5 are calculated as $0.207,0.494$ and as 0.153 , respectively. As shown in figure 8 , the correlation coefficient for Model 5 obtained is 0.705 . Thus, amongst the models with three input parameters, the Froude number $(F r)$ is identified as the most influenced parameter in predicting the ratio of the scour depth to the radius of the scour hole $\left(\mathrm{d}_{\mathrm{s}} / L\right)$ among the models with three input parameters. Models 6-11 predict scour values through a combination of two input parameters.

The values of RMSE and BIAS for Model 6 are calculated 0138 and 0.112 , respectively. Also, the values of MARE, $R$ and $\rho$ for this model are estimated 0.066, 0.976 and 0.037 , respectively. This model simulates about $83 \%$ of the results with an error less than $10 \%$ and $9 \%$ of the results have an error between 10 and $15 \%$. Based on the error distribution results, about $7 \%$ of the predicted scours have an error more than 15\%. Model 6 simulates scour using the Froude number $(F r)$ and ratio of the average diameter of sediments to the radius of the scour hole $\left(\mathrm{d}_{50} / L\right)$. Amongst the models with two input variables, Model 7 has the lowest error value $(M A R E=0.065, R M S E=0.135)$ and the highest correlation coefficient $(R=0.978)$. This model approximates more than $79 \%$ of scour values with an error less than $10 \%$ and about $15 \%$ of the results have an error between 10 and $15 \%$. Furthermore, about $5 \%$ of the data have an error more than $15 \%$. The BIAS, SI and $\rho$ indices for Model 7 are calculated $0.113,0.071$ and 0.036 , respectively. The model estimates the scour by means of the Froude number $(\mathrm{Fr})$ and the ratio of the flow depth to the radius of the scour hole $(\mathrm{h} / \mathrm{L})$. Amongst the models with two input variables, after Model 7, Model 8 has the highest accuracy. The model estimates the scour depth using the Froude number and the geometric standard deviation of sediment particle distribution. The MARE, RMSE and BIAS for this model are computed 0.065, 0.138 and 0.114, respectively. Based on the scatter plot results, the value of $R$ for this model is calculated 0.977 . Also, only $4 \%$ of the results predicted by

Table 4. $D R_{(\max )}, D R_{(\min )}$ and $D R_{(\text {ave })}$ for numerical models.

\begin{tabular}{lccc}
\hline & $D R_{(\max )}$ & $D R_{(\min )}$ & $D R_{(\text {ave })}$ \\
\hline Model 1 & 1.455 & 0.592 & 0.985 \\
Model 2 & 1.230 & 0.798 & 0.986 \\
Model 3 & 1.319 & 0.697 & 0.994 \\
Model 4 & 1.178 & 0.818 & 0.981 \\
Model 5 & 1.756 & 0.686 & 1.049 \\
Model 6 & 1.223 & 0.816 & 0.986 \\
Model 7 & 1.159 & 0.821 & 0.981 \\
Model 8 & 1.178 & 0.819 & 0.981 \\
Model 9 & 1.318 & 0.782 & 0.996 \\
Model 10 & 1.760 & 0.594 & 1.052 \\
Model 11 & 1.340 & 0.765 & 0.979 \\
\hline
\end{tabular}


Table 5. Comparison between the superior model and the previous studies.

\begin{tabular}{lcccccc}
\hline Models & $R$ & RMSE & MARE & MAPE & BIAS & SI \\
\hline ANFIS-GA/SVD 7 & 0.978 & 0.135 & 0.065 & - & 0.113 & 0.071 \\
Muzzammil [25] & 0.950 & 0.050 & - & 4.160 & - & - \\
Azamathulla [26] & 0.960 & 0.290 & - & - & - & - \\
Najafzadeh et al [27] & 0.960 & 0.530 & - & 0.726 & - & - \\
Moradi et al [33] & 0.970 & 0.154 & - & 7.87 & - & - \\
\hline
\end{tabular}

Model 8 have an error more than $15 \%$ and about $77 \%$ of the data have an error less than $10 \%$. About $24 \%$ of the predicted results by Model 9 have an error between 10 and $15 \%$. The value of the correlation coefficient for this model equals to 0.927 . This model simulates the depth of scour holes around bridge abutments as a function of $\mathrm{d}_{50} / L$ and $\mathrm{h} / \mathrm{L}$. It is worth noting that about $50 \%$ of the predicted data by the model have an error less than $10 \%$. In addition, the SI and $\rho$ for Model 9 are calculated 0.125 and 0.065 , respectively.

Model 10 simulates the scour by employing ratio of the average diameter of sediments to the radius of the scour hole $\left(\mathrm{d}_{50} / L\right)$ and the geometric standard deviation of sediment particle distribution $\left(\sigma_{g}\right)$. Amongst the models with two input variables, this model has the lowest correlation coefficient $(R=0.589)$. Based on the results of the error distribution, about $64 \%$ of the modeling results by Model 10 have an error more than $15 \%$. The values of MARE, $B I A S$ and $\rho$ for the model are obtained 0.217, 0.399 and 0.165 , respectively.

About $45 \%$ of the results simulated by Model 11 have an error less than $10 \%$, while about $22 \%$ of the data predicted by the model have an error less than $15 \%$. The model is a function of h/L and $\sigma_{g}$. The value of the Scatter Index for the model is also computed 0.134. The BIAS and $\rho$ for Model 11 are approximated 0.213 and 0.070 , respectively.

According to the analysis of the scour prediction results using the ANFIS-GA/SVD method, the Froude number $(F r)$ and the ratio of the flow depth to the radius of the scour hole $(\mathrm{h} / \mathrm{L})$ are identified as the most effective parameters on $\mathrm{d}_{\mathrm{s}} / L$.

The discrepancy ratio $\left(D R=\mathrm{d}_{\mathrm{s}} / L_{(\text {Pr edicted })} /\right.$ $\left.\mathrm{d}_{\mathrm{s}} / L_{\text {(observed })}\right)$ is introduced for examining sensitivity of values predicted by Model 1 to Model 11. The closeness of the discrepancy ratio to one indicates the closeness of simulated results to the observed values. For this purpose, the maximum, minimum and average of the $D R$ are listed in table 4. For Model 1, the values of $D R_{(\max )}, D R_{(\min )}$ and $D R_{\text {(ave) }}$ are obtained $1.455,0.592$ and 0.985 , in turn. Additionally, $D R_{(\text {ave })}$ for Model 2 and Model 3 are calculated 0.986 and 0.994 , respectively. $D R_{(\max )}$ and $D R_{(\min )}$ for Model 4 are forecasted 1.178 and 0.818 , respectively. One of the highest $D R_{(\max )}$ and lowest $D R_{(\min )}$ are calculated for Model $5\left(D R_{\max }=1.756, D R_{\min }=0.686\right)$. For this model, $D R_{(\text {(ave) }}$ is equal to 1.049 . For model $6, D R_{(\max )}, D R_{(\min )}$ and
$D R_{\text {(ave) }}$ are estimated $1.223,0.816$ and 0.986 , in turn. The lowest $D R_{(\max )}$ and the highest $D R_{(\min )}$ for Model 7 are computed 1.159 and 0.821 , respectively. $D R_{(\text {ave })}$ for Model 8 and Model 9 are obtained 0.981 and 0.996, in turn. For Model $10, D R_{(\min )}$ and $D R_{(\text {ave })}$ are predicted to be 0.594 and 1.052. In addition, $D R_{(\text {ave })}$ for Model 11 is also obtained equal to 0.979 .

\subsection{Comparison to previous works}

Based on the literature, some AI models simulated scour around abutments [25-27, 33]. In this section, a comparison between those works and the current study is presented. In table 5, the comparison between the superior model (ANFIS-GA/SVD 7) and Muzzammil [25], Azamathulla [26], Najafzadeh et al [27] and Moradi et al [33] is tabulated. Based on the table, ANFIS-GA/SVD has better performance in comparison to other soft computing (SC) studies when it comes scour around abutments. For instance, ANFIS-GA/SVD has the highest correlation coefficient amongst these SC techniques, meaning that $R$ index for the ANFIS-GA/SVD 7 is 0.978 , whilst the index for Muzzammil [25], Azamathulla [26] and Najafzadeh et al [27] is $0.950,0.960$ and 0.960 , respectively. In addition, the lowest RMSE value belongs to Muzzammil [25] $(R M S E=0.050)$ and this index for Azamathulla [26], Najafzadeh et al [27] and Moradi et al [33] is 0.290, 0.530 and 0.154 , respectively. Furthermore, scatter index (SI) for ANFIS-GA/SVD and Moradi et al [33] is 0.071 and 0.084 , in turn.

\section{Conclusion}

Scour estimation around the foundation of marine structures such as piers and abutments is one of the most important variables in designing this type of structures. In this study, the ANFIS was optimized using the evolutionary Pareto. In other words, the GA and SVD were utilized for optimal design of nonlinear antecedent parts and linear consequent parts of TSK-type of fuzzy rules of ANFIS. Thus, the ANFIS-GA/SVD model was defined for simulating the depth of scours around abutments. First, the parameters affecting the scour depth were identified. After that, 11 different models were developed through the combination of the parameters in order to model the scour. 
The numerical models simulated the scour values with reasonable accuracy. The superior model was introduced using a sensitivity analysis. The RMSE and MARE for the model were obtained 0.135 and 0.65 , respectively. For the superior model, the average value of the discrepancy ratio was calculated 0.981 . The sensitivity analysis showed that the Froude number $(F r)$ and the ratio of the flow depth to the radius of the scour hole $(h / L)$ were the most effective factors on the scour depth around abutments. Finally, results from the superior model and some previous investigations related to abutment scouring were presented which showed the ANFIS-GA/SVD had better performance.

\section{Acknowledgements}

We are grateful to Environmental Research Center of Razi University, Kermanshah, Iran for the support.

\section{References}

[1] Melville B W 1992 Local scour at bridge abutments. J. Hydraul. Eng. 118(4): 615-631

[2] Lim S Y 1997 Equilibrium clear-water scour around an abutment. J. Hydraul. Eng. 123(3): 237-243

[3] Melville B W 1997 Pier and abutment scour: integrated approach. J. Hydraul. Eng. 123(2): 125-136

[4] Oliveto G and Hager W H 2002 Temporal evolution of clearwater pier and abutment scour. J. Hydraul. Eng. 128(9): 811-820

[5] Coleman S E, Lauchlan C S and Melville B W 2003 Clearwater scour development at bridge abutments. J. Hydraul. Res. 41(5): 521-531

[6] Dey S and Barbhuiya A K 2004 Clear water scour at abutments. Proc. Inst. Civ. Eng-Water Manag. 157(2): 77-97

[7] Dey S and Barbhuiya A K 2004 Clear-water scour at abutments in thinly armored beds. J. Hydraul. Eng. 130(7): 622-634

[8] Radice A, Malavasi S and Ballio F 2008 Sediment kinematics in abutment scour. J. Hydraul. Eng. 134(2): 146-156

[9] Ballio F, Teruzzi A and Radice A 2009 Constriction effects in clear-water scour at abutments. J. Hydraul. Eng. 135(2): $140-145$

[10] Abdelaziz A A and Lim S Y 2017 Scour hole characteristics around abutment in compound channel. In: World Environmental and Water Resources Congress 2017

[11] Abid I and Hong S H 2018 Prediction of location of abutment and contraction scour hole for compound channels. In: World Environmental and Water Resources Congress 2018, Reston, VA: American Society of Civil Engineers, pp. 152-159

[12] Hong S H and Abid I 2019 Scour around an erodible abutment with riprap apron over time. J. Hydraul. Eng. 145(6): 06019007

[13] Ebtehaj I, Bonakdari H, Khoshbin F and Azimi H 2015 Pareto genetic design of group method of data handling type neural network for prediction discharge coefficient in rectangular side orifices. Flow. Meas. Instrum. 41: 67-74
[14] Ebtehaj I, Bonakdari H, Zaji A H, Azimi H and Sharifi A 2015 Gene expression programming to predict the discharge coefficient in rectangular side weirs. Appl. Soft. Comput. 35: 618-628

[15] Ebtehaj I and Bonakdari H 2013 Evaluation of sediment transport in sewer using artificial neural network. Eng. Appl. Comput. Fluid. Mech. 7(3): 382-392

[16] Ebtehaj I, Bonakdari H and Shamshirband S 2016 Extreme learning machine assessment for estimating sediment transport in open channels. Eng. Comput. 32: 1-14

[17] Azimi H, Bonakdari H, Ebtehaj I and Michelson D G 2018a A combined adaptive neuro-fuzzy inference system-firefly algorithm model for predicting the roller length of a hydraulic jump on a rough channel bed. Neural Comput. Appl. 29(6): 249-258

[18] Mogale D G, Kumar S K and Tiwari M K 2018 An MINLP model to support the movement and storage decisions of the Indian food grain supply chain. Control Eng. Pract. 70: 98-113

[19] Mogale D G, Kumar S K and Tiwari M K 2016 Two stage Indian food grain supply chain network transportation-allocation model. IFAC-Papers On Line 49(12): 1767-1772

[20] Azmathullah H M D, Deo M C and Deolalikar P B 2006 Estimation of scour below spillways using neural networks. J. Hydraul. Res. 44(1): 61-69

[21] Bateni S M and Jeng D S 2007 Estimation of pile group scour using adaptive neuro-fuzzy approach. Ocean Eng. 34(8-9): 1344-1354

[22] Firat M and Gungor M 2009 Generalized regression neural networks and feed forward neural networks for prediction of scour depth around bridge piers. Adv. Eng. Soft. 40(8): 731-737

[23] Kaya A 2010 Artificial neural network study of observed pattern of scour depth around bridge piers. Comput. Geotech. 37(3): 413-418

[24] Muzzammil M 2010 ANFIS approach to the scour depth prediction at a bridge abutment. J. Hydroinform. 12(4): 474-485

[25] Muzzammil M and Alam J 2011 ANFIS-based approach to scour depth prediction at abutments in armored beds. $J$. Hydroinform. 13(4): 699-713

[26] Azamathulla H M 2012 Gene-expression programming to predict scour at a bridge abutment. J. Hydroinform. 14(2): 324-331

[27] Najafzadeh M, Barani G A and Hessami Kermani M R 2013 Abutment scour in clear-water and live-bed conditions by GMDH network. Water. Sci. Tech. 67(5): 1121-1128

[28] Sharafi H, Ebtehaj I, Bonakdari H and Zaji A H 2016 Design of a support vector machine with different kernel functions to predict scour depth around bridge piers. Nat. Hazards 84(3): 2145-2162

[29] Ebtehaj I, Ahmed M A, Sattar A M A, Bonakdari H and Zaji A H 2016 Prediction of scour depth around bridge piers using self-adaptive extreme learning machine. J. Hydrodyn. 19(2): 207-224

[30] Azimi H, Bonakdari H, Ebtehaj I, Talesh S H A, Michelson D G and Jamali A 2017c Evolutionary Pareto optimization of an ANFIS network for modeling scour at pile groups in clear water condition. Fuzzy Set. Syst. 319: 50-69

[31] Chou J S and Pham A D 2014 Hybrid computational model for predicting bridge scour depth near piers and abutments. Autom. Constr. 48: 88-96 
[32] Mohammadpour R, Ghani A A, Vakili M and Sabzevari T 2016 Prediction of temporal scour hazard at bridge abutment. Nat. Hazards 80(3): 1891-1911

[33] Moradi F, Bonakdari H, Kisi O, Ebtehaj I, Shiri J and Gharabaghi B 2018 Abutment scour depth modeling using neuro-fuzzyembedded techniques. Mar. Georesour. Geotechnol. 37: 1-11

[34] Ebtehaj I, Bonakdari H, Moradi F, Gharabaghi B and Khozani Z S 2018 An integrated framework of extreme learning machines for predicting scour at pile groups in clear water condition. Coast. Eng. 135: 1-15

[35] Mogale D G, Kumar M, Kumar S K and Tiwari MK 2018 Grain silo location-allocation problem with dwell time for optimization of food grain supply chain network. Transp. Res. Part E Logist. Transp. Rev. 111: 40-69

[36] Azimi H, Shabanlou S, Ebtehaj I, Bonakdari H and Kardar S 2017 Combination of computational fluid dynamics, adaptive neuro-fuzzy inference system, and genetic algorithm for predicting discharge coefficient of rectangular side orifices. J. Irrig. Drain. Eng. 143(7): 04017015

[37] Dey S and Barbhuiya A K 2005 Time variation of scour at abutments. J. Hydraul. Eng. 131(1): 11-23

[38] Khoshbin F, Bonakdari H, Ashraf Talesh S H, Ebtehaj I, Zaji A H and Azimi H 2016 Adaptive neuro-fuzzy inference system multi-objective optimization using the genetic algorithm/singular value decomposition method for modelling the discharge coefficient in rectangular sharp-crested side weirs. Eng. Optim. 48(6): 933-948

[39] Golub G H and Reinsch C 1970 Singular value decomposition and least squares solutions. Numer. Math.14(5): 403-420

[40] Khalkhali A, Mostafapour M, Tabatabaie S M and Ansari B 2016 Multi-objective crashworthiness optimization of perforated square tubes using modified NSGAII and MOPSO. Struct. Multi. Optimize. 54: 45-61 